\title{
Critical evaluation of strength prediction methods for alkali-activated fly ash
}

\author{
K. L. Aughenbaugh • T. Williamson • \\ M. C. G. Juenger
}

Received: 6 August 2014/ Accepted: 24 November 2014/Published online: 23 December 2014

(C) The Author(s) 2014. This article is published with open access at Springerlink.com

\begin{abstract}
The literature contains many proposed methods for proportioning alkali-activated binders for maximum compressive strength. Many of these methods have been developed using metakaolin, which is a relatively pure aluminosilicate powder. In recent years, fly ash has become a more common aluminosilicate source for alkali activation. However, fly ash is a more complex material than metakaolin, and activated fly ash may not follow the same trends as activated metakaolin. In this study, literature-recommended strength prediction methods for alkali-activated binders, using metakaolin and fly ash, are reviewed and compared with the compressive strengths measured for eight Class F fly ash-based binders made by activation with sodium hydroxide solution. Of the eight fly ash binders in the study, six had correct performance predictions considering $\mathrm{SiO}_{2} /$ $\mathrm{Al}_{2} \mathrm{O}_{3}$ and $\mathrm{Na}_{2} \mathrm{O} / \mathrm{Al}_{2} \mathrm{O}_{3}$ optimal ratios developed for metakaolin. A published empirical equation developed to predict alkali-activated fly ash concrete strength correctly predicted relative strengths for six
\end{abstract}

\footnotetext{
K. L. Aughenbaugh ( $ه)$

Petroleum and Geosystems Engineering, The University of Texas at Austin, 200 E. Dean Keeton St., Stop C0300, Austin, TX 78712, USA

e-mail: katy.aughenbaugh@utexas.edu
}

T. Williamson · M. C. G. Juenger

Civil, Architectural and Environmental Engineering, The University of Texas at Austin, 301 E. Dean Keeton St.

C1758, Austin, TX 78712, USA of the eight fly ash binders. Modifier element content is another possible indicator of reactivity, and the fly ashes in this study generally showed that fly ashes with high contents of $\mathrm{Ca}^{2+}, \mathrm{Mg}^{2+}, \mathrm{Na}^{+}$, and $\mathrm{K}^{+}$were likely to produce strong binders, although the correlation shown here was not as strong as that shown in prior studies. This work demonstrates that, while the proposed prediction methods are generally adequate, they do not cover all fly ashes and more work is needed improve prediction methods and account for the behavior of outliers.

Keywords Geopolymer · Fly ash · Metakaolin · Strength $\cdot$ Proportioning

\section{Introduction}

Alkali-activated binders, which include the subset of materials known as geopolymer cements, are cementing materials that require the addition of alkalis in order to react in the presence of water and can be used in place of ordinary Portland cement in concrete construction [40]. Although development of alkaliactivated binders began in the early half of the 20th century [41] and was continued in the early 1970s by Glukhovsky [28], the development of alkali-activated aluminosilicate geopolymers in the late 1970s came from the need for new construction materials that were strong, durable, and non-flammable [14, 44]. Since 
then, geopolymers have moved into the forefront of a search for green building materials since they can be made with waste materials such as fly ash from coal burning power plants.

Designing geopolymer mixtures is dependent on mixing the appropriate activator with an aluminosilicate powder at an optimum ratio; however, deciding on an appropriate activator, activator concentration, and optimum proportioning ratio is not straightforward. Several methods have been reported in the literature for proportioning geopolymers including some in which several key ratios of constituent oxides are calculated $[5,12,19,20,27,43]$ and some in which a fixed solution-to-powder ratio is used [1, 24, 36, 45]. These methods are most often the result of testing geopolymers made from metakaolin, but the relatively consistent composition of metakaolin in terms of its inter-particle composition and composition of different lots of material means that the same mixture design techniques may not apply to fly ash based geopolymers, which are much more varied from particle to particle and lot to lot. A method to effectively proportion fly ash-based geopolymers for optimum property development is on the critical path for implementation of these materials.

In the work presented here, we reviewed the literature to compile the most promising proportioning methods for both metakaolin-based and fly ash basedgeopolymers. The use of metakaolin-based recommendations for proportioning was necessitated by the higher proportion of the literature that has studied this material and made recommendations on its raw material proportions. The effectiveness of these methods in predicting the relative compressive strengths for eight fly ash-based geopolymers activated with sodium hydroxide was evaluated.

\section{Background}

One of the most common methods of proportioning geopolymers is based on targeting specific oxide ratios in the material components. For example, the ratio of the aluminum and silicon constituents in a geopolymer is known to affect its properties greatly including compressive strength, flexural strength, and microstructure. [7, 12, 21, 27]. Further, the ratio of the alkalis to the aluminosilicate framework elements is also important to the property development of the material [20,21]. The literature includes a wide range of recommended molar ratios for use in proportioning the mixture, which are summarized in Table 1 for both metakaolin- and fly ash-based geopolymers.

While one can assume that all of the oxides in metakaolin are soluble in alkaline solution (albeit at varying rates), one cannot make the same assumption for fly ash since it contains a variety of soluble and insoluble crystalline and glassy phases. For fly ash, it is best to calculate molar oxide ratios of the reactive portion only of the fly ash, which can be approximated in a variety of ways, typically through chemical tests [25] or using x-ray diffraction (XRD) to quantify nonreactive crystalline phases $[10,48]$. The non-crystalline portion is also called the bulk glassy phase in the material and is generally assumed to be reactive for the purposes of molar oxide ratio proportioning [31]. However, it does not does not fully describe the availability of the elements contained in the glassy material to dissolve in solution (nor the kinetics of dissolution), the minor elements contained in the material, or the presence of unburnt carbon or sulfate; thus, use of the ratio proportioning method for alkaliactivated fly ash design must be used with these caveats.

The ratio method of proportioning geopolymers typically includes optimizing the $\mathrm{SiO}_{2} / \mathrm{Al}_{2} \mathrm{O}_{3},\left(\mathrm{Na}_{2} \mathrm{O}\right.$ or $\left.\mathrm{K}_{2} \mathrm{O}\right) / \mathrm{Al}_{2} \mathrm{O}_{3}, \mathrm{H}_{2} \mathrm{O} / \mathrm{Na}_{2} \mathrm{O}$, and/or $\mathrm{Na}_{2} \mathrm{O} / \mathrm{SiO}_{2}$ ratios in a mixture. The $\mathrm{SiO}_{2} / \mathrm{Al}_{2} \mathrm{O}_{3}$ range recommended to form a metakaolin geopolymer with a desirable microstructure and strength has been suggested as 2-24, admittedly a wide range, with a ratio of 16 resulting in the highest measured crushing strengths [27]. Other studies examining varying $\mathrm{SiO}_{2} / \mathrm{Al}_{2} \mathrm{O}_{3}$ ratios in metakaolin geopolymers have shown optimum ratios in the range of 2.0-4.3 as shown in Table 1 [5, 43, 48]. For fly ashes, these values are somewhat different. It was reported in a study on high-calcium fly ash geopolymer that the $\mathrm{SiO}_{2} / \mathrm{Al}_{2} \mathrm{O}_{3}>4.3$ resulted in decreased compressive strength [12]. Similarly, for Class F fly ashes with equivalent vitreous silica, it has been reported that higher amounts of vitreous alumina resulted in improved reactivity of the fly ashes when activated as geopolymers, suggesting that low $\mathrm{SiO}_{2} /$ $\mathrm{Al}_{2} \mathrm{O}_{3}$ values are preferable [26].

The $\mathrm{Na}_{2} \mathrm{O}+\mathrm{K}_{2} \mathrm{O}$ to alumina ratio has been recommended to be approximately equal to 1 , since the alkali charge balances the aluminosilicate tetrahedra in geopolymer gel, which is negatively charged due 
Table 1 Literature review of favorable molar oxide ratios in geopolymers

\begin{tabular}{lllllll}
\hline Study & Aluminosilicate source & $\mathrm{SiO}_{2} / \mathrm{Al}_{2} \mathrm{O}_{3}$ & $\mathrm{Na}_{2} \mathrm{O} / \mathrm{SiO}_{2}$ & $\mathrm{H}_{2} \mathrm{O} / \mathrm{Na}_{2} \mathrm{O}$ & $\mathrm{Na}_{2} \mathrm{O} / \mathrm{Al}_{2} \mathrm{O}_{3}$ & $\mathrm{M}_{2} \mathrm{O}^{*} / \mathrm{Al}_{2} \mathrm{O}_{3}$ \\
\hline Davidovits [13] & Metakaolin & 4.0 & $0.25-0.28$ & $16-17.5$ & - & $1.0-1.14$ \\
Barbosa et al. [5] & Metakaolin & 3.3 & 0.25 & 10 & $\sim 1.0$ & - \\
Rowles and O'Connor [43]** & Metakaolin & 2.83 & 0.32 & - & 0.92 & - \\
Duxson et al. [20] & Metakaolin & 2.15 & - & - & - & - \\
Fletcher et al. [27] & $\begin{array}{c}\text { Metakaolin; } \\
\text {-alumina }\end{array}$ & 2 and 16 & 0.3 & 11 & 0.88 and 5 & - \\
Duxson et al. [19, 21]** & Metakaolin & 1.87 & - & - & - & - \\
Williams and van Riessen [48] & Class F fly ash & 2.0 & - & - & 1.0 & - \\
and metakaolin & & & & & - \\
Chindaprasirt et al. [12] & Class C fly ash & $3.20-3.70$ & - & - & - & - \\
Results summary & & $2.0-4.3$ & $0.25-0.32$ & $10-17.5$ & Alkali to alumina \\
& & & & & ratio should be $\sim 1$ \\
\hline
\end{tabular}

$* \mathrm{M}_{2} \mathrm{O}=\mathrm{Na}_{2} \mathrm{O}+\mathrm{K}_{2} \mathrm{O}$

** Indicates that the reported value was calculated from elemental ratios given by the original authors

to the inclusion of aluminum $[5,33,36,42]$. It has also been reported that too much sodium (i.e. a high $\mathrm{Na}_{2} \mathrm{O} /$ $\mathrm{Al}_{2} \mathrm{O}_{3}$ ) can increase carbonation at the surface of the geopolymer and, therefore, the sodium oxide content should be minimized to be approximately equal to the amount of alumina for that reason as well [5].

Given the limited degrees of freedom in the system, the sodium oxide to silica ratio is often simply reported rather than optimized. For a given $\mathrm{SiO}_{2} / \mathrm{Al}_{2} \mathrm{O}_{3}$ ratio, and $\mathrm{Na}_{2} \mathrm{O} / \mathrm{Al}_{2} \mathrm{O}_{3}$ ratio in a geopolymer, the sodium oxide to silica ratio is not further changeable. However, it is typically low, at approximately $0.25-0.3$ as reported in the literature [5, 13, 27, 43].

The use of solution-to-solid precursor (metakaolin or fly ash) ratios may be used to proportion the geopolymers based on adequate workability of the slurry $[1,24,36,45]$. The use of water-solids ratios may also be used for proportioning, in which the dissolved solids in the solution are considered part of the solids content of the material. Like in portland cements, excess water present in the geopolymer mixture negatively influences the hardened geopolymer properties such as microstructure, porosity and strength development, so it must be minimized $[5,45]$. Conversely, water is necessary to facilitate the reactions between activator and aluminosilicate powder and to make the cement flowable, so the need for water must be balanced by its negative effect on late age properties [39]. Heah [30] reported that a kaolin-based geopolymer cement required a liquid-to-solid ratio of 1.0 to develop the highest strength, while Al Bakri et al. (1) reported that an activator-to-fly ash ratio of 0.4 maximized geopolymerization in a fly ash-based geopolymer paste. The viscosity of the activating solution increases with increasing dissolved sodium, potassium and/or silica in the activating solution, but increased viscosity also leads to increased liquid demand in the geopolymer [11, 23]. Therefore, a disadvantage of the solution-to-precursor method of proportioning is that there may be a certain level of trial-and-error testing necessary to determine whether the proportions chosen result in suitable rheological properties for the mixture and hardened properties in the reacted geopolymer.

Another approach to proportioning geopolymers is to develop empirical prediction equations based on full-factorial testing of a range of materials, relating independent variables to a dependent variable such as strength. One such method has been proposed by Diaz Loya et al. [16, 17] to evaluate the suitability of fly ashes for alkali-activation based on the vitreous content of the ashes, the loss on ignition, and the mean particle size. This method was developed after testing of geopolymer concretes made using sodium hydroxide and sodium silicate activator, which were cured $24 \mathrm{~h}$ at $23{ }^{\circ} \mathrm{C}, 72 \mathrm{~h}$ at $60{ }^{\circ} \mathrm{C}$, and $24 \mathrm{~h}$ at $23{ }^{\circ} \mathrm{C}$, for a total of 5 days. The compressive strength results were then used to develop the relationship between the properties of the fly ash used and the compressive strength of the geopolymer concrete. The relationship between the inputs of the equation was refined using a step-wise regression analysis. 
The relative amount of network modifying elements $\left(\mathrm{Ca}^{2+}, \mathrm{Mg}^{2+}, \mathrm{Na}^{+}, \mathrm{K}^{+}\right)$present in Class $\mathrm{F}$ ash has also been used previously as an indicator for geopolymer compressive strength. These elements primarily play a charge-balancing role by balancing the negative charge of tetrahedral aluminum, allowing the aluminum to take on 4-coordination, which has greater solubility than the 6-coordination that it would otherwise take [22]. If additional network modifiers are available after balancing tetrahedral aluminum, the remaining network modifying elements tend to alter the glass structure of fly ash by bonding with oxygen atoms, preventing the oxygen atoms from forming a bridge between adjacent $\mathrm{SiO}_{4}$ tetrahedra. The presence of these non-bridging oxygen (NBO) atoms also increases the fly ash reactivity $[16,22]$.

Duxson and Provis [22] developed a ternary diagram based on relative amounts of silica, alumina, and network modifier. By compiling results of fly ashes tested in several previous studies, they found that compressive strength generally increased with network modifier content, although a direct comparison of quantitative results was not possible since the data were sourced from studies with a wide range of experimental conditions. Oh et al. [37] examined the correlation between material properties of six Class $\mathrm{F}$ fly ashes and resulting geopolymer compressive strength and concluded that network modifier content was the best predictor of geopolymer performance of the properties tested, with the result that compressive strength plotted against network modifier content had an exponential curve with $R^{2}=0.952$.

Since one of the primary roles of the network modifying elements is to balance the negative charge of aluminum tetrahedra, the sum of charges is used to quantify the network modifying capacity. The total network modifier content is then $2 \mathrm{Ca}^{2+}+2 \mathrm{Mg}^{2+}+-$ $\mathrm{Na}^{+}+\mathrm{K}^{+}$and as this value increases, so does the capacity to balance negatively charged tetrahedral aluminum and to increase disorder by disallowing oxygen atoms to bridge adjacent tetrahedra. In addition to comparing the network modifier directly to strength, the ratio of non-bridging oxygen atoms per tetrahedron (NBO/T) has also been used to predict geopolymer strength. This approach was first taken by Bumrongjaroen et al. [8] to predict reactivity of fly ash used as a supplementary cementitious material in high-performance portland cement concrete and has since been used to predict the reactivity of fly ash used in geopolymers by Diaz-Loya et al. [17]. The NBO/T ratio is calculated by subtracting the content of aluminum and iron from the total network modifier content (because network modifying elements will balance charges in $\mathrm{Al}^{3+}$ and $\mathrm{Fe}^{3+}$ tetrahedra before bonding with oxygen to form NBO) and dividing the result by the number of silicon, aluminum, and iron atoms (the atoms that form tetrahedra). Diaz-Loya et al. [17] found a relatively strong linear fit (no $R^{2}$ value provided) between geopolymer compressive strength and fly ash NBO/T for 38 high-calcium fly ashes.

The study presented in this paper was designed to assess the compressive strength development of geopolymers made with eight Class F fly ashes and a single concentration of sodium hydroxide solution and to use the results to critically evaluate literature proportioning and property-prediction methods. Properties including oxide analysis (by x-ray fluorescence), crystalline composition and bulk glassy phase/vitreous composition using XRD coupled with Rietveld analysis, loss-on-ignition, and particle size distribution were measured for each fly ash. The results were compared to the recommendations in the literature for proportioning geopolymers with high strength.

\section{Materials and methods}

Eight Class F (ASTM C618-12, [3]) fly ashes from the United States were selected for this work. The eight fly ashes represented a variety of compositions while all being classified as Class F by ASTM C618. The oxide contents of the fly ashes provided by the manufacturers are given in Table 2. Three fly ashes (BBR, CC, and LEGS) were selected due to their general similarity to fly ashes that were found to perform favorably as geopolymers in research on Australian fly ashes [35]. The AT fly ash was selected for its high alkali content. BC was selected due to its near-zero calcium content, and the FO fly ash and ML fly ash were chosen for their relatively low calcium contents.

\subsection{Particle size analysis}

The particle size distributions of the ashes were measured using a Spraytec laser particle size analyzer by Malvern Instruments and Spraytec software. A small quantity of the fly ash was weighed and mixed with degassed isopropyl alcohol (99\% purity) before testing. The fly 
Table 2 Oxide analysis (mass\%) provided by manufacturer

\begin{tabular}{lllllllll}
\hline Oxide & AT (mass\%) & BC (mass\%) & BBR (mass\%) & CE (mass\%) & CC (mass\%) & FO (mass\%) & LEGS (mass\%) & ML (mass\%) \\
\hline $\mathrm{Al}_{2} \mathrm{O}_{3}$ & 21.6 & 30.5 & 18.4 & 16.4 & 21 & 25.1 & 17.8 & 19.9 \\
$\mathrm{SiO}_{2}$ & 47.7 & 55.8 & 48.4 & 54.1 & 48.2 & 59.4 & 54.1 & 54.8 \\
$\mathrm{CaO}$ & 12.3 & 1.2 & 14.1 & 11.2 & 12.8 & 5.6 & 10.7 & 9.4 \\
$\mathrm{Fe}_{2} \mathrm{O}_{3}$ & 4.2 & 4.6 & 7.9 & 6 & 4.9 & 5.6 & 7.7 & 8.7 \\
$\mathrm{~K}_{2} \mathrm{O}$ & 0.9 & 2.3 & 1.1 & 1.9 & 1.2 & 1 & 1.4 & 1.1 \\
$\mathrm{MgO}$ & 2.7 & 0.7 & 2.2 & 4.1 & 3.4 & 0.9 & 2.3 & 2.4 \\
$\mathrm{Na}_{2} \mathrm{O}$ & 1.9 & 0.3 & 0.6 & 1.2 & 1.5 & 0.2 & 0.5 & 0.6 \\
$\mathrm{SO}_{3}$ & 1.2 & 0.1 & 0.4 & 0.6 & 0.3 & 0.4 & 0.4 & 0.5 \\
$\mathrm{TiO}_{2}$ & 1 & $n / a$ & 1.2 & 1 & 1 & 1.1 & 1.2 & $\mathrm{n} / \mathrm{a}$ \\
$\mathrm{LOI}$ & 0.8 & 2.4 & 0.5 & 0.2 & 0.8 & 0.2 & 0.1 & 0.1 \\
\hline
\end{tabular}

The oxides do not sum to $100 \%$ due to unreported elements in small amounts

ash/isopropyl mixture was poured into the machine, and a stirrer kept the fly ash suspended as the mixture was pumped through the measurement chamber. Each fly ash was tested once for particle size analysis.

\subsection{X-ray diffraction \& rietveld analysis}

Each fly ash was subjected to XRD testing using a Siemens D500 diffractometer operated at $40 \mathrm{kV}$ and $30 \mathrm{~mA}$. The scans ranged from $15^{\circ} 2 \theta$ to $65^{\circ} 2 \theta$ with step size $0.02^{\circ} 2 \theta$ and a $6 \mathrm{~s}$ dwell time. Zincite $(\mathrm{ZnO})$ was used as an internal standard for XRD quantitative analysis $[6,18]$. The zincite was interground with the fly ash at $10 \%$ of the mass of the sample [32] using an agate mortar and pestle and a small amount of ethanol as a dispersant. Beginning with an accurate starting model of the XRD pattern, a refinement was completed to accurately calculate the amount of phase in each of the specimen [50]. Using the known mass percent of the internal standard, the data were renormalized to calculate the amount of crystalline and bulk amorphous phases.

In this study, three separate samples of each ash were scanned and quantitatively analyzed by Rietveld analysis using the TOPAS Academic software package, and the results were averaged. The bulk oxide amounts were then corrected to reflect "vitreous" amounts of the oxide by subtracting the amount of the phase contained in crystalline phases from the bulk oxide content.

\subsection{Compressive strength of geopolymer mortars}

Mortar cubes were made for compressive strength analysis of all eight fly ashes mixed using the same activator, proportions and curing regime. The activating solution used was $8 \mathrm{~mol} / \mathrm{L} \mathrm{NaOH}$ solution. The mortars were proportioned following the solution-to-powder (s/p) method after Fernández-Jiménez et al. [24]. Other authors have since used this proportioning method, as reported in the introduction. The mortar cube preparation method given in ASTM Standard C109 (ASTM C 109-09, [2]) was followed (with some modification) for mixing, placing, and curing the specimens. The s/p ratio (by mass) was not determined individually for each fly ash as suggested in ASTM C109 for water-to-cement ratio (w/c) determination. Rather, an $\mathrm{s} / \mathrm{p}$ that was appropriate for all eight fly ashes was determined through trial mixing small amounts of mortars until a mixture that was not too dry and not too runny was obtained for all eight ashes. This $\mathrm{s} / \mathrm{p}$ value turned out to be 0.485 (by mass), the same as that recommended in ASTM C109 for use in portland cement mortars. Keeping a constant $s / p$ was done in an effort to compare fly ashes mixed with the same amount of sodium hydroxide solution. The ratios of the relevant constituent oxides were then calculated for each mix for comparison to literature values. The geopolymers were cured at room temperature $\left(23{ }^{\circ} \mathrm{C}\right)$ to remove the effects of heat on the reaction with the alkaline activator. In addition, while ASTM C109 recommends that portland cement mortars should be removed from the molds at 1 day, this was determined too short an interval for most fly ash-based geopolymers cured at $23{ }^{\circ} \mathrm{C}$, so the mortars remained in their molds for 7 day, covered, in a $23{ }^{\circ} \mathrm{C} 100 \% \mathrm{RH}$ fog room. Finally, instead of storage in limewater, the mortar cubes to be tested at 28 day were patted surface dry, placed in sealed plastic bags, and stored in a room at $23{ }^{\circ} \mathrm{C}$. One set of 
three mortar cubes was made for testing at 7 and 28 days for each of the eight fly ashes.

\section{Results and discussion}

\subsection{Particle size distribution}

The cumulative particle size distribution for the fly ashes is plotted in Fig. 1. The $\mathrm{d}_{10}, \mathrm{~d}_{50}$, and $\mathrm{d}_{90}$ values for each fly ash are presented in Table 3. These data were used as inputs in the model of Diaz-Loya et al. [16].

\subsection{Crystalline and bulk glassy phase composition}

The crystalline phases were identified for each fly ash, and all identified were assumed to be essentially inert in alkaline solution [19]. To determine the amount of each bulk oxide that was present in vitreous form, the crystalline phases were subtracted from the bulk oxide composition of the fly ash. The vitreous amounts of each of the three major constituents of the fly ash, alumina, calcium oxide, and silica, are presented in Fig. 2, with the remaining vitreous oxides summed as "other vitreous." The total amount of vitreous material in each fly ash can also be read from this plot, and ranged from 60 to 90 mass\%.

\subsection{Measured compressive strength}

The measured compressive strengths of geopolymer mortar cubes are presented in Fig. 3. At 28 days, the

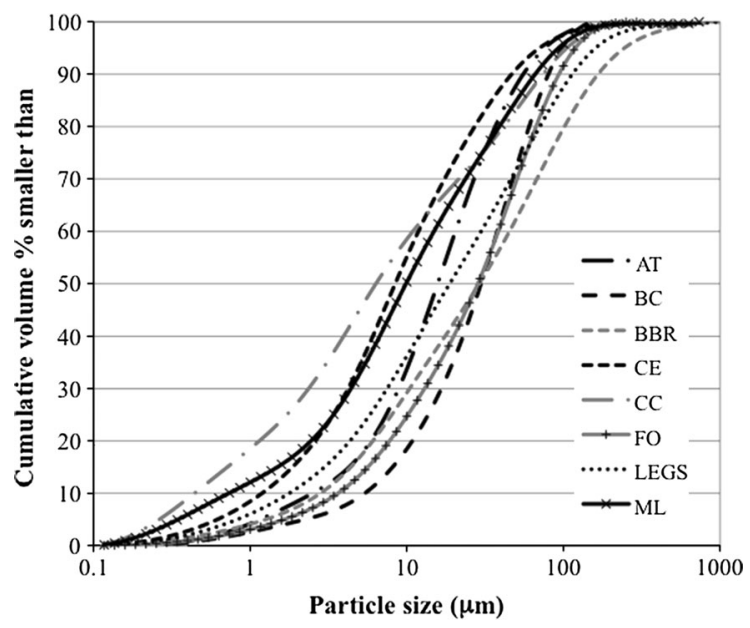

Fig. 1 Particle size distributions for all eight fly ashes measured by laser PSD
Table 3 Tenth $\left(\mathrm{d}_{10}\right)$, fiftieth $\left(\mathrm{d}_{50}\right)$, and ninetieth $\left(\mathrm{d}_{90}\right)$ percentile particle sizes for the eight fly ashes in this study

\begin{tabular}{llll}
\hline Fly ash & $\mathrm{d}_{10}(\mu \mathrm{m})$ & $\mathrm{d}_{50}(\mu \mathrm{m})$ & $\mathrm{d}_{90}(\mu \mathrm{m})$ \\
\hline AT & 2.5 & 15.8 & 54.1 \\
BC & 5.9 & 31 & 84.2 \\
BBR & 2.9 & 29.3 & 158.5 \\
CE & 1.2 & 8.6 & 46.4 \\
CC & 0.5 & 6.3 & 73.6 \\
FO & 4.0 & 29.3 & 100 \\
LEGS & 1.8 & 18.5 & 116.6 \\
ML & 0.7 & 10 & 63.1 \\
\hline
\end{tabular}

different reactivities of the fly ashes with the activating solution $(8 \mathrm{~mol} / \mathrm{L} \mathrm{NaOH})$ were apparent by differences in the compressive strengths of the geopolymers. From these results three categories were devised for descriptive purposes of the geopolymer performance after curing at $23{ }^{\circ} \mathrm{C}$ : for compressive strength over $10 \mathrm{MPa}$ the geopolymer was considered strong, for compressive strength of 5-10 MPa the geopolymer was considered moderately strong, and for compressive strength under $5 \mathrm{MPa}$ the geopolymer was considered poor. It is worth noting that these strengths are low compared to most concretes, and stronger geopolymers can be produced through optimization of the constituent materials and/or heat curing. However, the goal of this study was to compare fly ash reactivities with identical proportioning and curing conditions and

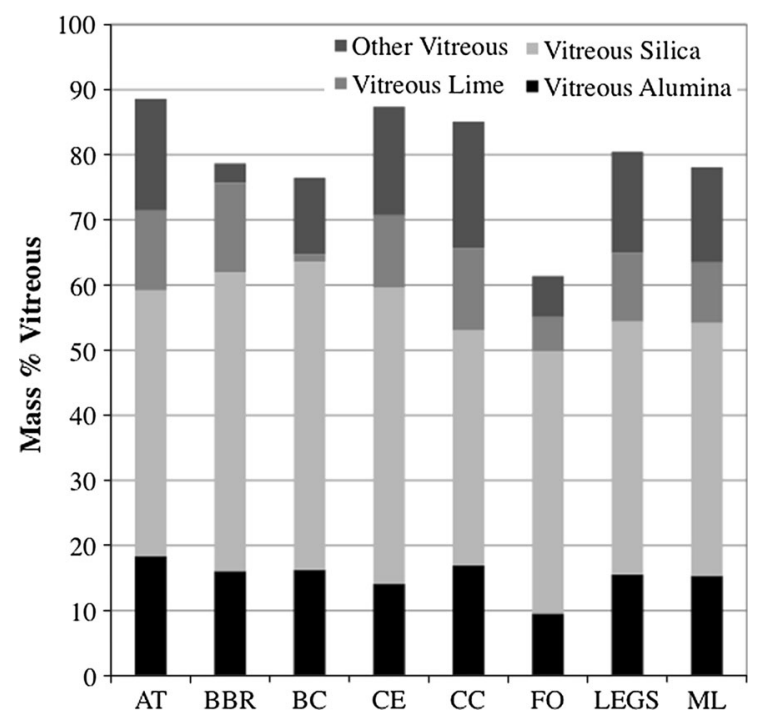

Fig. 2 Vitreous content of the fly ash shown as networkforming oxides 


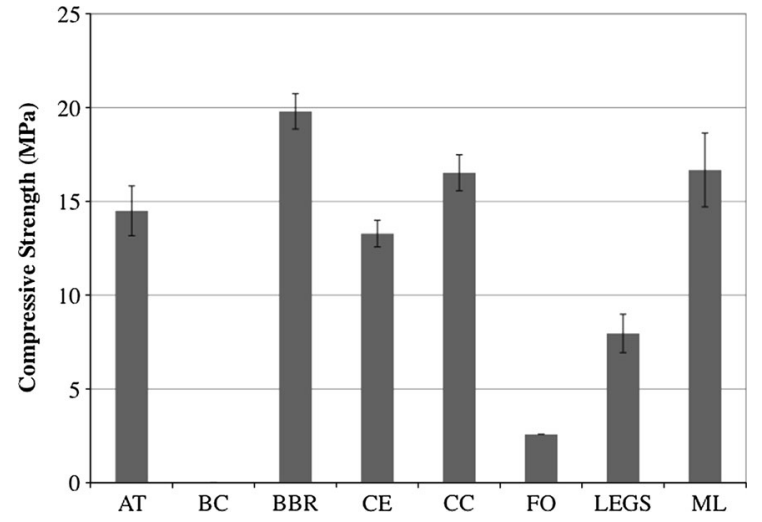

Fig. 328 day compressive strength for fly ashes activated with $8 \mathrm{M} \mathrm{NaOH}$ solution at a 0.485 solution-to-powder ratio and cured at $23{ }^{\circ} \mathrm{C}(n=3$, error bars denote high and low values)

without the addition of heat or aqueous silicate. Direct comparison of strength values between studies is misleading because of varying experimental conditions, so the categories of strength were used to compare predicted performance to measured performance. These strengths are compared to the predicted strength performance in the following sections.

\subsection{Molar oxide ratio comparison to literature recommendations}

The molar vitreous oxide ratios calculated for each fly ash are presented in Table 4 . The ranges of molar $\mathrm{SiO}_{2} / \mathrm{Al}_{2} \mathrm{O}_{3}, \mathrm{Na}_{2} \mathrm{O} / \mathrm{SiO}_{2}$, and $\mathrm{Na}_{2} \mathrm{O} / \mathrm{Al}_{2} \mathrm{O}_{3}$ ratio values suggested by the authors cited in Table 1 are given for reference. The amount of sodium oxide for these calculations was calculated based on a mortar made using $8 \mathrm{~mol} / \mathrm{L} \mathrm{NaOH}$ and a 0.485 solution-to-powder ratio, including the $\mathrm{Na}_{2} \mathrm{O}$ contribution from both the fly ash and the activator. The $\mathrm{Na}_{2} \mathrm{O}$ source in these geopolymers was primarily from the activating solution, since sodium in the fly ashes was present only between 0.15 and 4.2 mass $\% \mathrm{Na}_{2} \mathrm{O}$, as measured in oxide analysis (Table 1). The ratio methods described earlier sometimes described the alkali component as " $\mathrm{M}_{2} \mathrm{O}$," which is either $\mathrm{Na}_{2} \mathrm{O}$ or $\mathrm{K}_{2} \mathrm{O}$ or their sum. In this work the $\mathrm{Na}_{2} \mathrm{O}$ was used, and the $\mathrm{K}_{2} \mathrm{O}$, which was contained in the fly ash in very small amounts, was neglected.

The vitreous molar constituent ratios for $\mathrm{SiO}_{2} /$ $\mathrm{Al}_{2} \mathrm{O}_{3}$ of all eight fly ashes revealed that those that fell within the recommended range from the literature were AT, CC, LEGS, and ML. Geopolymers made
Table 4 Molar ratios of for 0.485 solution-to-powder geopolymer mixtures made with $8 \mathrm{M} \mathrm{NaOH}$ solution (bold, italicized values indicate that they are outside of the recommended range)

\begin{tabular}{llll}
\hline Fly Ash & \multicolumn{3}{l}{ Molar ratios } \\
\cline { 2 - 4 } & $\begin{array}{l}\mathrm{SiO}_{2} / \\
\mathrm{Al}_{2} \mathrm{O}_{3}\end{array}$ & $\begin{array}{l}\mathrm{Na}_{2} \mathrm{O} / \\
\mathrm{SiO}_{2}\end{array}$ & $\begin{array}{l}\mathrm{Na}_{2} \mathrm{O}^{\mathrm{b}} / \\
\mathrm{Al}_{2} \mathrm{O}_{3}\end{array}$ \\
\hline $\mathrm{AT}$ & 3.79 & 0.27 & 1.01 \\
$\mathrm{BC}$ & $\mathbf{4 . 9 9}$ & 0.2 & 0.99 \\
$\mathrm{BBR}$ & $\mathbf{4 . 8 4}$ & 0.21 & 1.02 \\
$\mathrm{CE}$ & $\mathbf{5 . 5 2}$ & 0.22 & $\mathbf{1 . 2 3}$ \\
$\mathrm{CC}$ & 3.64 & 0.28 & 1.04 \\
FO & $\mathbf{7 . 2}$ & 0.23 & $\mathbf{1 . 6 4}$ \\
LEGS & 4.24 & 0.25 & 1.05 \\
ML & 4.29 & 0.25 & 1.07 \\
Literature & $2.83-4.3$ & $0.25-0.32$ & $0.88-1.14$ \\
recommendations & & & \\
\hline
\end{tabular}

with these fly ashes were all designated as strong based on the compressive strength results, except for LEGS, which was moderately strong. The two fly ashes that made poor geopolymers had very high amorphous molar $\mathrm{SiO}_{2} / \mathrm{Al}_{2} \mathrm{O}_{3}$ ratios of $4.99(\mathrm{BC})$ and 7.2 (FO), which were well above the recommended value of 4.3. However, the CE fly ash had a high molar $\mathrm{SiO}_{2} / \mathrm{Al}_{2} \mathrm{O}_{3}$ of 5.52 and was found to make a strong geopolymer, so close but not strict agreement was found between the literature-recommended vitreous phase silica to alumina ratios and strength.

The alkalis in the system are also known to affect the properties of hardened geopolymer cements, and the recommended ranges for ratios containing alkali oxide were reported in Table 1. Two activated fly ashes had $\mathrm{Na}_{2} \mathrm{O} / \mathrm{Al}_{2} \mathrm{O}_{3}$, which should be around 1.0, that fell outside of the bound. The FO fly ash geopolymer had a high $\mathrm{Na}_{2} \mathrm{O} / \mathrm{Al}_{2} \mathrm{O}_{3}$ of 1.64 and it had low compressive strength at 28 days, as would be expected. The CE fly ash had a $\mathrm{Na}_{2} \mathrm{O} / \mathrm{Al}_{2} \mathrm{O}_{3}$ of 1.23 , which was high relative to the recommendations, but its 28 days compressive strength placed it among the strong geopolymers. This could mean that for some fly ashes, being above the recommended sodium oxide to alumina ratio is acceptable. However, all of the cubes exhibited a slight amount of efflorescence at 28 days, so the excess sodium may not have been chemically incorporated into the gel, resulting in a lower sodium oxide to alumina ratio in the gel. From another perspective, the $\mathrm{BC}$ geopolymer contained nearly 
exactly the recommended value of $\mathrm{Na}_{2} \mathrm{O} / \mathrm{Al}_{2} \mathrm{O}_{3}$; however, the $\mathrm{BC}$ geopolymer performed very poorly when activated, gaining no measurable compressive strength. $\mathrm{BC}$ also had a high $\mathrm{SiO}_{2} / \mathrm{Al}_{2} \mathrm{O}_{3}$ and high LOI, both of which may have been determining factors of its measured compressive strength when activated as a geopolymer. All of the fly ashes were within the recommended sodium oxide to silica composition ranges, which should be between 0.25 and 0.32 , as shown in Table 1 . As previously mentioned, this value is no longer changeable when the $\mathrm{SiO}_{2} / \mathrm{Al}_{2} \mathrm{O}_{3}$ and $\mathrm{Na}_{2} \mathrm{O} / \mathrm{Al}_{2} \mathrm{O}_{3}$ are fixed.

In general, proportioning fly ash geopolymers using recommended oxide ratios adequately allows for optimization of geopolymer compressive strength, particularly when using vitreous $\mathrm{SiO}_{2} / \mathrm{Al}_{2} \mathrm{O}_{3}$. For the fly ashes studied here, some mixtures that fell outside of the recommended ranges performed poorly, as expected, while others performed well, as expected. Geopolymers made from LEGS fly ash performed slightly worse than predicted based on vitreous $\mathrm{SiO}_{2} /$ $\mathrm{Al}_{2} \mathrm{O}_{3}$, while the $\mathrm{CE}$ geopolymer behaved better than predicted based on both $\mathrm{SiO}_{2} / \mathrm{Al}_{2} \mathrm{O}_{3}$ and $\mathrm{Na}_{2} \mathrm{O} / \mathrm{Al}_{2} \mathrm{O}_{3}$. It is likely that there are other factors superseding the molar oxide ratios that determine strength in these outlier fly ashes. One possible explanation for this result, is in the recognized fact that there are multiple glassy phases within a fly ash sample [10, 15, 31, 34], and these glasses can react differently when exposed to caustic solutions [4, 9]. Further, the method of examining oxide ratios neglects the role of particle size in determining geopolymer performance.

\subsection{Compressive strength predictions based on an empirical model}

The empirical equation developed by Diaz-Loya et al. [16] to determine relative compressive strengths of geopolymer concrete was applied to the fly ashes in this data set to validate the predictive equation. The results are plotted in Fig. 4, with the normalized calculated strength predictions ( $y$ axis) compared to the normalized measured strength values ( $x$ axis) for each fly ash (at 28 days). The strengths are normalized to the strongest geopolymer for each data set. A line with slope of 1 shows the line of equality. In all cases the scaled predicted strength from the empirical equation was higher than the measured strength, which was expected due to differences in the material tested

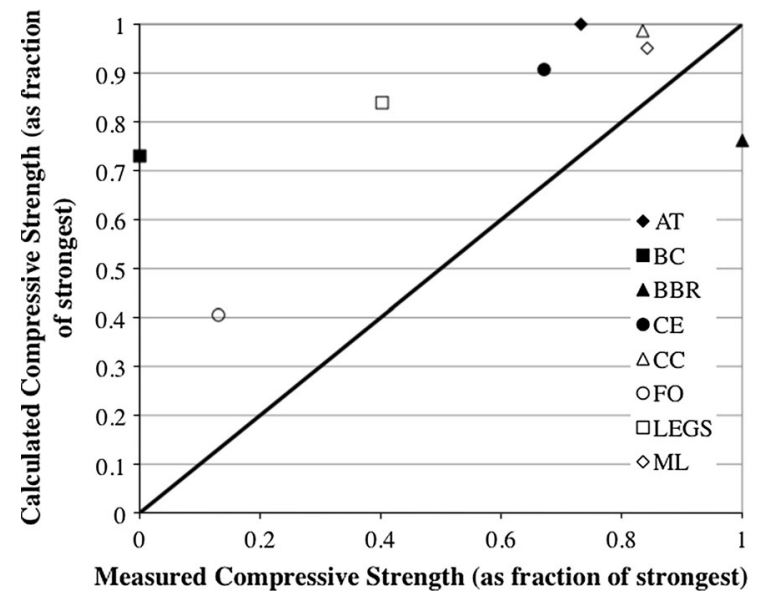

Fig. 4 Predicted compressive strengths for geopolymer concretes following Diaz-Loya et al. [16] compared to measured compressive strengths of geopolymer mortars (MPa)

(concrete vs. mortar), the activator (waterglass vs. no waterglas, water-solids ratio), and curing conditions (heat cured vs. ambient cured). However, the general trends in relative strengths are noted and discussed here. If one assumes that scaling effects have skewed the data toward higher predicted strengths than measured strengths, the most obvious deviations in measured strength from predicted strength are the BC and BBR geopolymers. The strength of the BBR geopolymer is under-predicted and the strength of the BC geopolymer is over-predicted. The BC geopolymer was predicted to have compressive strength similar to the CE and LEGS geopolymers, but the BC geopolymer did not develop any compressive strength by 28 days. Conversely, the BBR geopolymer produced the highest measured compressive strength in mortars, but was predicted to have a lower compressive strength than most of the others.

The results showed that while six of the eight of the fly ashes were correctly predicted to have good compressive strengths, some of the fly ashes were outliers to the method developed by Diaz-Loya et al. [16]. The inputs to the equation, vitreous contents of the main network-building constituents $\left(\mathrm{SiO}_{2}, \mathrm{Al}_{2} \mathrm{O}_{3}\right.$, and $\left.\mathrm{CaO}\right), \mathrm{LOI}$, and $\mathrm{d}_{50}$, were ranked by the authors in terms of weighting in the equation, with the result that the $d_{50}$ was the strongest indicator of high strength, followed by the vitreous alumina, the LOI, the vitreous silica, and finally the vitreous lime. Therefore, fly ashes with very coarse $\mathrm{d}_{50}$ sizes would be expected to have lower strengths, especially if they also had low vitreous alumina (the second strongest indicator of 
strength). The three coarsest fly ashes (based upon $\mathrm{d}_{50}$ ) in this study were BC, BBR, and FO. Of these fly ashes, the FO had the lowest vitreous alumina in the study and was correctly predicted to have the low strength. The BC had a moderate amount of vitreous alumina, but it had overall low total vitreous content, which led to its low predicted strength. This observation points out a flaw in the methods that examine contents and ratios of vitreous oxides: all vitreous content in the ash, including the total (as shown in Fig. 3), should also be addressed, not just the relative values of a few oxides. The BBR was correctly predicted to have relatively high strength despite its large particle size, although it was under-predicted for its measured strength. Its under-prediction was likely due to the weighting applied to the $\mathrm{d}_{50}$ particle size in the equation, which would have reduced its predicted strength.

In general, the equation developed by Diaz-Loya et al. [16] performed well in predicting the performance of these fly ashes as geopolymers, but there were some deviations from the predictions that require further investigation. The over and under-predicted fly ashes may have factors that influenced their actual behavior that were not accounted for optimally in the predictive equation. For example, the strength of BC may have been over-predicted because the equation only addresses the content of certain vitreous oxides, not the total vitreous content (Fig. 3). BBR may have been under-predicted because of the relative weighting given to particle size in the equation compared to other factors.

\subsection{Network modifier content}

Network modifier content is expressed as an atomic percent and was determined by converting oxide weight percentages (obtained from XRF) to oxide molar ratios and then to element atomic ratios. The network modifier content is taken as the sum of charges, or $2 \mathrm{Ca}+\mathrm{Na}+\mathrm{K}+2 \mathrm{Mg}$ (see Table 5), since the elements with a +2 charge have twice the capacity to balance the negative charges- of tetrahedral alumina.

Duxson and Provis [22] developed a classification system for geopolymer aluminosilicate source material based on the contents of silica, alumina, and combined network modifiers based on charge-balancing capacity $\left(2 \mathrm{Ca}^{2+}+2 \mathrm{Mg}^{2+}+\mathrm{Na}^{+},+\mathrm{K}^{+}\right)$. A recent RILEM state-of-the-art report [38] presents a ternary diagram with data compiled from various previous studies, ranking the relative strength of geopolymers produced from each fly ash. Data for the Class F fly ashes from the RILEM report are presented in the ternary diagram in Fig. 5 with the eight ashes from this study overlaid as well (shown in black). It should be noted that in the ternary diagram, elements other than $\mathrm{Si}, \mathrm{Al}, \mathrm{Ca}, \mathrm{Mg}$, $\mathrm{Na}$, and $\mathrm{K}$ are not included and the compositions were normalized accordingly. As a result the network modifier contents in the ternary diagram differ slightly from those in the direct comparisons, which include all of the elements measured in the oxide analysis.

The three ovals on the diagram show general compositional regions where fly ashes from the previous studies as well as this study produced geopolymers of low, medium, and high strength. The divisions between regions are not precise, but there is an obvious trend of fly ashes with higher network modifying agents producing stronger geopolymers and the fly ashes from this study align well with the previous data. The only exception is the LEGS fly ash, which had moderate measured strength but is predicted on the diagram to have high strength.

Figure 6 shows the measured compressive strength of each geopolymer as a function of the fly ash network modifier content, following the method developed by $\mathrm{Oh}$ et al. [37]. Values varied between 8.03 and $41.7 \%$, and, as expected, strength generally increased as network modifier content increased. An exponential curve was fit to the data with $R^{2}=0.761$ (the BC fly ash had a strength of 0 and so was omitted

Table 5 Fly ash elemental atomic composition of network modifiers obtained from XRF

\begin{tabular}{lrrrrrrrr}
\hline Element (atomic\%) & AT & BC & BBR & CE & CC & FO & LEGS & ML \\
\hline $\mathrm{Ca}$ & 13.2 & 1.3 & 15.4 & 11.7 & 13.6 & 5.8 & 11.5 & 9.9 \\
$\mathrm{Mg}$ & 4.0 & 1.1 & 3.3 & 6.1 & 5.1 & 1.4 & 3.5 & 3.6 \\
$\mathrm{Na}$ & 3.7 & 0.5 & 1.3 & 2.2 & 2.9 & 0.3 & 0.9 & 1.2 \\
$\mathrm{~K}$ & 1.1 & 2.9 & 1.5 & 2.3 & 1.5 & 1.2 & 1.8 & 1.4 \\
$2 \mathrm{Ca}+\mathrm{Na}+\mathrm{K}+2 \mathrm{Mg}$ & 39.3 & 8.0 & 40.1 & 40.2 & 41.7 & 15.9 & 32.6 & 29.6 \\
\hline
\end{tabular}




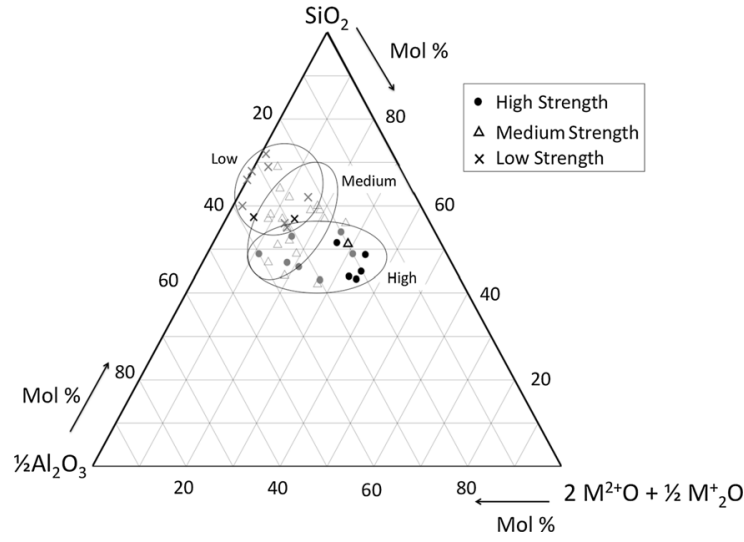

Fig. 5 Ternary plot showing the relationship between geopolymer compressive strength and fly ash oxide composition, based on the diagram presented by RILEM report chapter 4 (shown in gray) and the 8 additional fly ashes of this study (shown in black)

from the exponential fit). The degree of fit between compressive strength and network modifier content from this study was not as strong as that obtained by Oh et al. [37], which had $R^{2}=0.952$ when plotted on an exponential curve. The difference in degree of fit may be attributed to the differences in s/p ratio ( 0.485 in this study versus 0.6 ), activating solution concentration ( 8 vs. 5 and $10 \mathrm{M}$ ), and curing temperatures (23 vs. 30 and $60^{\circ} \mathrm{C}$ ), as well as a wider variety of fly ash compositions examined in this study. The obvious outlier on this curve is the ML fly ash, whose strength is under-predicted and one could consider that BBR is slightly under-predicted while LEGS is slightly overpredicted.
The ratio $\mathrm{NBO} / \mathrm{T}$ is another way to express the effect of fly ash network modifiers on geopolymer strength [17] and assumes that any network modifiers that are available after charge-balancing tetrahedral $\mathrm{Al}^{3+}$ and $\mathrm{Fe}^{3+}$ will prevent oxygen bridges from forming, which increases the reactivity of the fly ash. The highest possible value for $\mathrm{NBO} / \mathrm{T}$ is 4 and implies that no tetrahedra are oxygen-bridged, but typical values for fly ash are much lower. A negative value indicates that not all of the $\mathrm{Al}^{3+}$ and $\mathrm{Fe}^{3+}$ are chargebalanced by network modifiers and therefore no network modifying elements remain to prevent oxygen from bridging neighboring tetrahedra. In this case, the unbalanced aluminum takes on 6-coordination which has lower reactivity compared to the 4-coordination aluminum that is formed in the presence of sufficient charge balancing cations [22]. Figure 7 presents the average 28-day geopolymer compressive strengths versus fly ash $\mathrm{NBO} / \mathrm{T}$ (calculated using bulk oxide contents from XRF analysis). Values of NBO/T ranged from -0.329 to 0.220 and there was generally an increase in compressive strength as NBO/T increased, as expected. A linear trend line was fit to the data with $R^{2}=0.715$. The fly ashes that fall furthest from the line are the ML and BBR, which are under-predicted, and the LEGS and CE, which are over-predicted.

The network modifier content and $\mathrm{NBO} / \mathrm{T}$ as described in this section are closely related in that they are both metrics used to quantify the relative amount of alkali and alkali earth metals present in fly ash. While both methods demonstrated a general trend
Fig. 6 Geopolymer paste 28-day compressive strength as a function of fly ash network modifier content

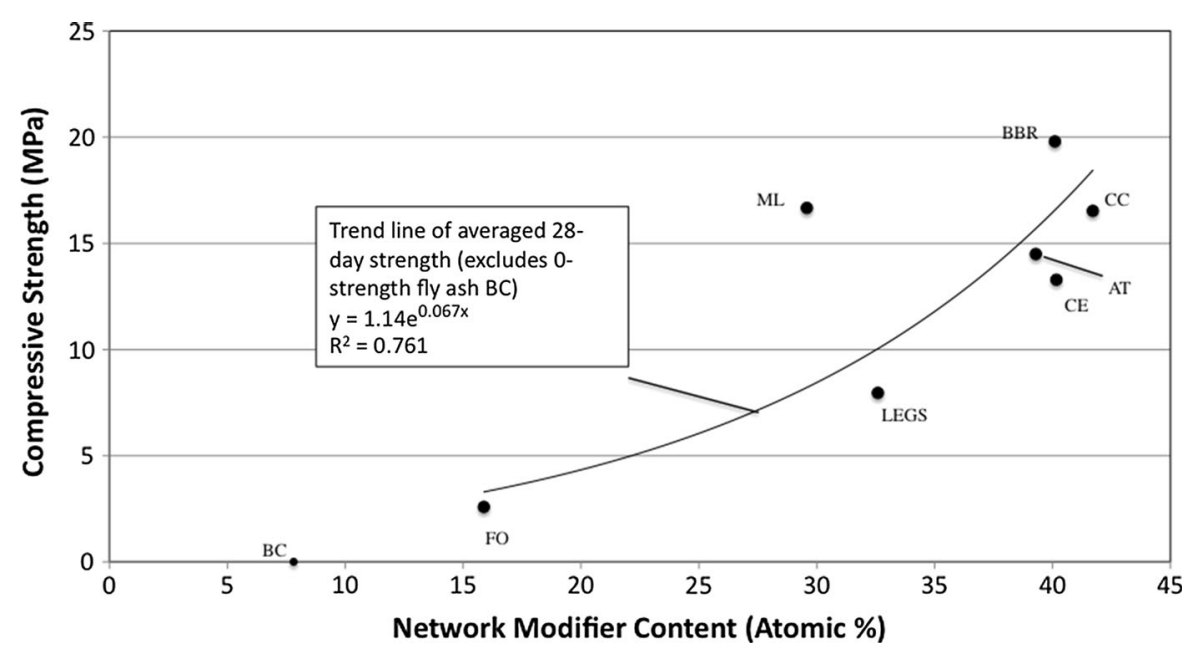


Fig. 7 Geopolymer paste 28-day compressive strength as a function of fly ash $\mathrm{NBO} / \mathrm{T}$

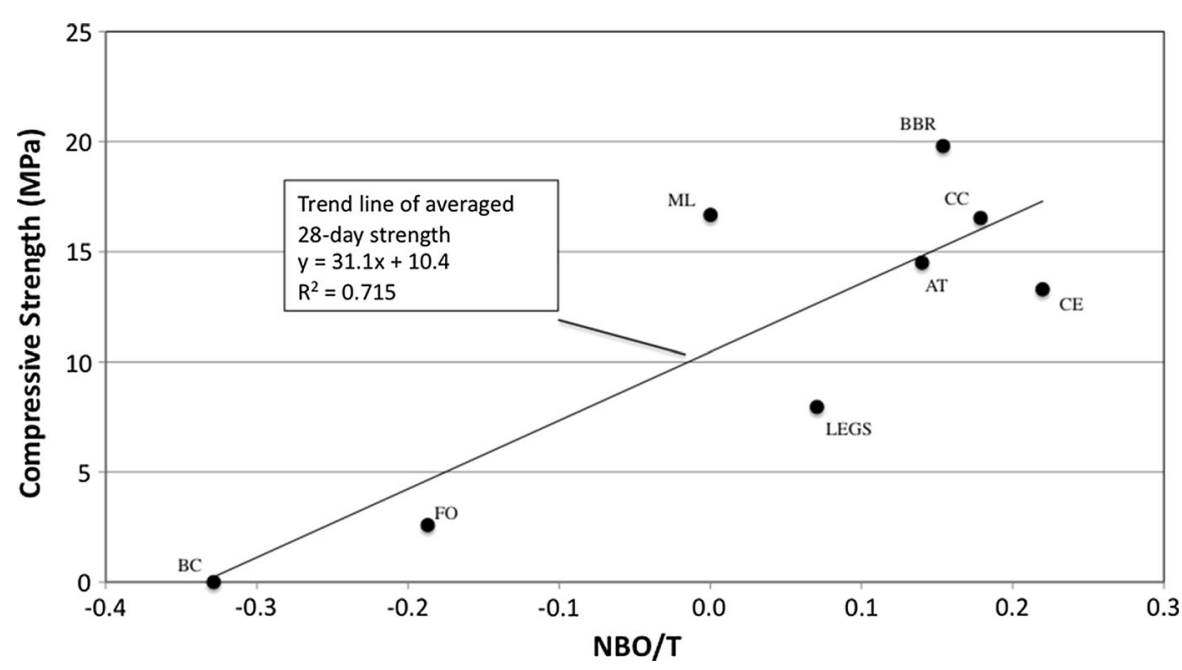

of increasing geopolymer compressive strength with increasing fly ash network modifiers, neither fit is strong enough to merit the use of network modifier content alone as a basis for a precise prediction of compressive strength. For both the network modifier content and NBO/T ML and BBR produced geopolymers with higher strengths than expected, and LEGS produced a geopolymer with lower strength than expected.

One complicating factor in understanding the mechanism by which network modifiers impact compressive strength involves the various roles calcium can play to impact geopolymer performance. As discussed earlier, calcium can function as a network modifier by balancing the negatively charged tetrahedral aluminum or by disrupting oxygen bridges between silicon tetrahedron, either of which leads to a more reactive fly ash. However, calcium present in fly ash can lead to calcium bearing hydrate phases such as calcium silicate hydrate $(\mathrm{C}-\mathrm{S}-\mathrm{H})$, the primary portland cement hydration product, and calcium aluminosilicate hydrate (C-A-S-H), both of which also contribute to compressive strength [19, 46, 49]. Furthermore, Yip et al. [49] found that calcium hydroxide formation becomes more favorable than the formation of C-S-H and C-A-S-H in the presence of sufficient alkali hydroxides. Therefore, while analyzing a fly ash with higher calcium content, it is not straightforward to determine whether the improved strength is result of the calcium acting as a network modifier or a result of the formation of calcium bearing hydrate phases.

\section{Discussion}

All of the methods examined for predicting geopolymer strength were adequate for proportioning alkali-activated fly ash with the predictions being accurate for the majority of the fly ashes examined in this study. The molar oxide ratio methods correctly predicted strength for all but two fly ashes, LEGS, which was slightly overpredicted and $\mathrm{CE}$, which was under-predicted. The $\mathrm{SiO}_{2} / \mathrm{Al}_{2} \mathrm{O}_{3}$ ratio was a better predictor than the $\mathrm{Na}_{2} \mathrm{O}$ / $\mathrm{Al}_{2} \mathrm{O}_{3}$ ratio. Using an empirical model to predict strength based on chemical and physical characteristics of the fly ash [16] also correctly predicted relative strengths for most of the fly ash, with the notable exceptions of highly over-predicting the strength of the BC geopolymer and slightly under-predicting the strength of the BBR geopolymer. Selecting fly ashes based on network modifier content, through placement on a ternary diagram [38], use of an exponential fitted curve [37], or a linear fit using NBO/T [17] are also adequate methods with good property prediction for the majority of fly ashes in this study. Interestingly, the LEGS fly ash geopolymer strength was also over-predicted when plotting network modifiers on a ternary phase diagram. However, the exponential fit method correctly predicted the LEGS geopolymer strength and under-predicted that of ML and BBR. Similarly, the NBO/T method over-predicted LEGS and under-predicted ML and BBR.

It should be noted that the trends observed in this study are for one specific set of experimental conditions, notably a constant activating solution and 
ambient curing. Previous studies have evaluated the effect of curing temperature [29, 47] and proportioning (i.e. activating solution-to-powder ratio) $[1,29]$ on geopolymer compressive strength and it is possible that higher curing temperatures or alternate materials proportioning could influence the accuracy of the predictive methods studied here.

Given that these methods all did an adequate job of predicting performance in this study, it appears that they are examining appropriate factors in the fly ash and the activating solution. However, given that there are several outliers in the small data set examined in this study, each method seems to be missing a critical part of the puzzle that would take the guess-work out of proportioning alkali-activated fly ash and facilitate field implementation. The results of this critical evaluation suggest that a method that accounts for both physical aspects of a fly ash, such as particle size, compositional aspects of the fly ash, such as network modifier content, minor element content, and vitreous content, and compositional aspects of the system, such as molar oxide ratios, could provide better prediction results. Further, a better understanding of the glassy phases in fly ash and their relative solubilities in alkaline solution would also serve to clarify discrepancies in fly ash behavior.

\section{Conclusions}

The study presented in this paper compared the measured compressive strengths of geopolymers mixed with $8 \mathrm{M} \mathrm{NaOH}$ solution and cured at $23{ }^{\circ} \mathrm{C}$ with the predicted properties of a geopolymer using several methods reported in the literature. Following are conclusions to be drawn from these data:

- The use of vitreous $\mathrm{SiO}_{2} / \mathrm{Al}_{2} \mathrm{O}_{3}$ ratios to predict strength correctly assigned six of the eight fly ashes and was a better predictor than the $\mathrm{Na}_{2} \mathrm{O}$ / $\mathrm{Al}_{2} \mathrm{O}_{3}$ ratio. In the cases where molar oxide ratios failed to predict performance, the reasons may be related to factors that are not accounted for in this method, including particle size, total vitreous content, and composition of the vitreous phases.

- The use of the equation developed by Diaz-Loya et al. [16] for predicting geopolymer compressive strength was appropriate for six of the eight fly ashes. The authors' process of refining the equation showed that the $\mathrm{d}_{50}$ particle size and the vitreous alumina content of the raw material were the two strongest indicators that a fly ash will have good compressive strength as a geopolymer. The relative weighting of the parameters, especially particle size, and the consideration of total vitreous content merit more investigation.

- The use of network modifier content (either directly or by using NBO/T) demonstrated a general trend with regards to geopolymer compressive strength but should not be used alone to form precise predictions of strength since it does not account for total vitreous content, the distribution of network modifiers among the glassy phases present, the contribution of calcium toward C-S-H or C-A-S-H binding phases, or particle size.

In order to properly predict the strength of alkaliactivated fly ash, it is clear that more information is needed about the fly ashes and the geopolymers that they form, and this information should be incorporated into prediction models. Most of the strength prediction methods only take into account limited aspects of the fly ash and/or the fly ash-activator system. A combined method that accounts for both physical and chemical aspects of the material is warranted, including both particle size and vitreous composition. However, it should be noted that even these types of analyses may come up short if they neglect to account for the distribution of oxides within the distinct glassy phases that make up each fly ash, which are known to have different reactivities, and if they neglect the role of calcium in forming hydrated phases distinct from the geopolymer network. It can be summarized that we currently have the ability to adequately predict the relative strengths of alkali-activated fly ash, but more work is needed to develop truly accurate prediction models.

Acknowledgments The authors would like to gratefully acknowledge funding from the National Science Foundation (Grant \# CMMI 0926627) and the Federal Highway Administration (DTFH61-13-H-00011) for sponsoring this work.

Open Access This article is distributed under the terms of the Creative Commons Attribution License which permits any use, distribution, and reproduction in any medium, provided the original author(s) and the source are credited. 


\section{References}

1. Al Bakri A, Kamarudin H, Khairul Nizar I, Bnhussain M, Zarina Y, Rafiza A (2011) Correlation between $\mathrm{Na}_{2} \mathrm{SiO}_{3} /$ $\mathrm{NaOH}$ Ratio and fly ash/alkaline activator ratio to the strength of geopolymer. Adv Mater Res 341-342:189-193. doi:10.4028/www.scientific.net/AMR.341-342.189

2. ASTM C 109 (2008) Test method for compressive strength of hydraulic cement mortars (Using 2-in. or [50-mm] Cube Specimens). ASTM International, West Conshocken. doi: 10.1520/C0109_C0109M-08. Accessed from http://www. astm.org/DATABASE.CART/HISTORICAL/ C109C109M-08.htm

3. ASTM C618-12 (2012) Specification for coal fly ash and raw or calcined natural Pozzolan for use in concrete. ASTM International, West Conshocken. doi: 10.1520/C0618-12A. Accessed from http://www.astm.org/Standards/C618.htm

4. Aughenbaugh K, Chancey R, Stutzman P, Juenger M, Fowler D (2013) An examination of the reactivity of fly ash in cementitious pore solutions. Mater Struct 46(5):869-880. doi:10.1617/s11527-012-9939-6

5. Barbosa V, MacKenzie K, Thaumaturgo C (2000) Synthesis and characterisation of materials based on inorganic polymers of alumina and silica: sodium polysialate polymers. Int J Inorg Mater 2(4):309-317. doi:10.1016/S1466-6049(00) 00041-6

6. Buchwald A (2006) Influence of geopolymer composition on their structure and properties. In: Buchwald A, Dombrowski K, Weil M (eds) Workshop proceeding geopolymer binders: interdependence of composition, structure and properties. Bauhaus-University Weimar, Shaker Verlag, Germany (pp. 55-70)

7. Buchwald A, Zellmann H, Kaps C (2011) Condensation of aluminosilicate gels - model system for geopolymer binders. J Non-Cryst Solids 357(5):1376-1382. doi:10.1016/j. jnoncrysol.2010.12.036

8. Bumrongjaroen W, Swatekititham S, Livingston R, Schweitzer J (2007) Synthetic glass models for investigating fly ash reactivity. ACI Spec. Publication, Farmington, pp 227-242

9. Chancey R (2008) Characterization of crystalline and amorphous phases and respective reactivities in a Class F fly ash. Dissertation, The University of Texas at Austin. Accessed from http://ezproxy.lib.utexas.edu/login?url=http:// search.proquest.com/docview/304474740?accountid=7118

10. Chancey R, Stutzman P, Juenger M, Fowler D (2010) Comprehensive phase characterization of crystalline and amorphous phases of a Class F fly ash. Cem Concr Res 40(1):146-156. doi:10.1016/j.cemconres.2009.08.029

11. Chindaprasirt P, Chareerat T, Sirivivatnanon V (2007) Workability and strength of coarse high calcium fly ash geopolymer. Cem Concr Comp 29(3):224-229. doi:10. 1016/j.cemconcomp.2006.11.002

12. Chindaprasirt $P$, De Silva $P$, Sagoe-Crentsil K, Hanjitsuwan $S$ (2012) Effect of $\mathrm{SiO}_{2}$ and $\mathrm{Al}_{2} \mathrm{O}_{3}$ on the setting and hardening of high calcium fly ash-based geopolymer systems. J Mater Sci 47(12):4876-4883. doi:10.1007/s10853-012-6353-y

13. Davidovits J (1982, September 14) Mineral polymers and methods of making them. US Patent 4,349,386. Accessed from http://www.freepatentsonline.com/4349386.html
14. Davidovits J (1991) Geopolymers: inorganic polymeric new materials. J Therm Anal 37(8):1633-1656

15. Dhole R (2010) Sulfate resistance of high calcium fly ash concrete. Thesis, University of New Brunswick. Accessed from http://ezproxy.lib.utexas.edu/login?url=http://search. proquest.com/docview/944409026?accountid=7118

16. Diaz-Loya EI, Allouche EN, Cahoy D (2013a) Statisticalbased approach for predicting the mechanical properties of geopolymer concretes. In: Struble L, Hicks JK (eds) Geopolymer binder systems (pp. 119-143). ASTM International, West Conshohocken. Accessed from http://www. astm.org/DIGITAL_LIBRARY/STP/PAGES/STP156620 120080.htm

17. Diaz-Loya EI, Kinney F, Rios CAO (2013) Reactivity indicators for activated high-calcium fly ash-based binders, vol 294. ACI Special Publication, Farmington, pp 1-22

18. Dombrowski K, Buchwald A, Weil M (2007) The influence of calcium content on the structure and thermal performance of fly ash based geopolymers. J Mater Sci 42(9):3033-3043. doi:10.1007/s10853-006-0532-7

19. Duxson P, Fernández-Jiménez A, Provis J, Lukey G, Palomo A, Van Deventer J (2007) Geopolymer technology: the current state of the art. J Mater Sci 42(9):2917-2933. doi:10.1007/s10853-006-0637-z

20. Duxson P, Lukey G, Separovic F, Van Deventer J (2005) Effect of alkali cations on aluminum incorporation in geopolymeric gels. Ind Eng Chem Res 44(4):832-839. doi:10. 1021/ie0494216

21. Duxson P, Mallicoat S, Lukey G, Kriven W, van Deventer J (2007) The effect of alkali and Si/Al ratio on the development of mechanical properties of metakaolin-based geopolymers. Colloids Surf A 292(1):8-20. doi:10.1016/j. colsurfa.2006.05.044

22. Duxson P, Provis J (2008) Designing precursors for geopolymer cements. J Am Ceram Soc 91(12):3864-3869. doi:10.1111/j.1551-2916.2008.02787.x

23. Favier A, Hot J, Habert G, Roussel N, d'Espinose de Lacaillerie JB (2014) Flow properties of MK-based geopolymer pastes. A comparative study with standard Portland cement pastes. Soft Matter 10:1134. doi: 10.1039/c3sm51889b

24. Fernández-Jiménez A, de la Torre A, Palomo A, LópezOlmo G, Alonso M, Aranda M (2006) Quantitative determination of phases in the alkaline activation of fly ash. Part II: degree of reaction. Fuel 85(14-15):1960-1969. doi:10. 1016/j.fuel.2006.04.006

25. Fernández-Jiménez A, Palomo A (2003) Characterisation of fly ashes. Potential reactivity as alkaline cements. Fuel 82(18):2259-2265. doi:10.1016/S0016-2361(03)00194-7

26. Fernández-Jiménez A, Palomo A, Sobrados I, Sanz J (2006) The role played by the reactive alumina content in the alkaline activation of fly ashes. Micropor Mesopor Mat 91(1-3):111-119. doi:10.1016/j.micromeso.2005.11.015

27. Fletcher R, MacKenzie K, Nicholson C, Shimada S (2005) The composition range of aluminosilicate geopolymers. J Eur Ceram Soc 25(9):1471-1477. doi:10.1016/j. jeurceramsoc.2004.06.001

28. Glukhovsky (Glukovoski) V (1979) Alkali-earth binders and concretes produced with them. Kiev, USSR: Visheka Shkola 
29. Hardjito D, Wallah SE, Sumajouw DMJ, Rangan BV (2004) On the development of fly ash-based geopolymer concrete. ACI Mater J 101(6):467-472

30. Heah C, Kamarudin H, Mustafa Al Bakri A, Bnhussain M, Luqman M, Khairul Nizar I, Ruzaidi C, Liew Y (2012) Study on solids-to-liquid and alkaline activator ratios on Kaolin-based geopolymers. Constr Build Mater 35:912-922. doi:10.1016/j.conbuildmat.2012.04.102

31. Hemmings R, Berry E (1987) On the glass in coal fly ashes: recent advances. MRS Online Proc Lib, 113. doi:10.1557/ PROC-113-3

32. Jones RC, Babcock CJ, Knowlton WB (2000) Estimation of the total amorphous content of Hawai'i soils by the Rietveld method. Soil Sci Soc Am J 64(3):1100. doi:10.2136/ sssaj2000.6431100x

33. Khale D, Chaudhary R (2007) Mechanism of geopolymerization and factors influencing its development: a review. J Mater Sci 42(3):729-746. doi:10.1007/s 10853-006-0401-4

34. Kruse K (2012) Characterization of high-calcium fly ash for evaluating the sulfate resistance of concrete. Thesis, The University of Texas at Austin

35. Lloyd R (2008) The durability of inorganic polymer cements. Dissertation, University of Melbourne, Melbourne

36. Oh J, Monteiro P, Jun S, Choi S, Clark S (2010) The evolution of strength and crystalline phases for alkali-activated ground blast furnace slag and fly ash-based geopolymers. Cem Concr Res 40(2):189-196. doi:10.1016/j.cemconres.2009.10.010

37. Oh JE, Jun Y, Jeong Y, Monteiro PJM (unpublished manuscript) The importance of the network-modifying element content in fly ash as a simple measure to predict its strength potential for alkali-activation. Cem Concr Compos

38. Provis J, Deventer JSJ (2014) Alkali activated materialsstate-of-the-Art Report, RILEM TC 224-AAM. Springer. Accessed from http://www.springer.com/engineering/civil+ engineering/book/978-94-007-7671-5

39. Provis J, van Deventer JSJ (2007) Geopolymerisation kinetics. 2. Reaction kinetic modelling. Chem Eng Sci 62(9): 2318-2329. doi:10.1016/j.ces.2007.01.028
40. Provis JL, Bernal SA (2014) Geopolymers and related alkaliactivated materials. Annu Rev Mater Res 2014.44:299-327. Downloaded from www.annualreviews.org 10/13/14

41. Purdon A (1940) The action of alkalis on blast-furnace slag. J Soc Chem Ind- Trans Commun 59:191-202

42. Rees C, Provis J, Lukey G, van Deventer J (2007) In situ ATR-FTIR study of the early stages of fly ash geopolymer gel formation. Langmuir 23(17):9076-9082

43. Rowles M, O'Connor B (2003) Chemical optimisation of the compressive strength of aluminosilicate geopolymers synthesised by sodium silicate activation of metakaolinite. J Mater Chem 13(5):1161-1165. doi:10.1039/b212629j

44. Roy D (1999) Alkali activated cement opportunities and challenges. Cem Concr Res 29:249-254. doi:10.1016/ S0008-8846(98)00093-3

45. Ruiz-Santaquiteria C, Skibsted J, Fernández-Jiménez A, Palomo A (2012) Alkaline solution/binder ratio as a determining factor in the alkaline activation of aluminosilicates. Cem Concr Res 42(9):1242-1251. doi:10.1016/j.cem conres.2012.05.019

46. Temuujin J, van Riessen A, Williams R (2009) Influence of calcium compounds on the mechanical properties of fly ash geopolymer pastes. J Hazard Mater 167:82-88

47. van Jaarsveld JGS, van Deventer JSJ, Lukey GC (2002) The effect of composition and temperature on the properties of fly ash- and kaolinite-based geopolymers. Chem Eng J 89:63-73

48. Williams R, van Riessen A (2010) Determination of the reactive component of fly ashes for geopolymer production using XRF and XRD. Fuel 89(12):3683-3692. doi:10.1016/ j.fuel.2010.07.031

49. Yip CK, Lukey GC, van Deventer JSJ (2005) The coexistence of geopolymeric gel and calcium silicate hydrate at the early stage of alkaline activation. Cem Concr Res 35:1688-1697

50. Young R (1993) Introduction to the Rietveld method. In: The Rietveld method. Oxford University Press, Oxford (pp. 1-38) 